\title{
ADMINISTRACIÓN BUROCRÁTICA, DE GERENCIA PÚBLICA Y GOBERNANZA EN LOS PROGRAMAS ALIMENTARIOS DE ARGENTINA DESDE 1983
}

\author{
Food Programs and Their Governance, Public Management and \\ Bureaucratic Administration since 1983 in Argentina
}

\author{
María Victoria Sordini'
}

\begin{abstract}
Resumen
El objetivo de este trabajo es observar la percepción de los técnicos y profesionales de la administración pública sobre el modelo burocrático, de gerencia pública y de gobernanza para la gestión e implementación de los programas alimentarios entre 1983 y 2018 en Argentina. Los diversos modelos de administración se cristalizan en las prácticas del saber-hacer de quienes diseñaron, gestionaron e implementaron los programas denotando las tensiones que se generan entre la política y la administración. El propósito de este trabajo es reconocer las rupturas y continuidades en los modelos de administración para comprender la complejidad del oficio de "hacer" políticas públicas en la democracia contemporánea. El diseño del estudio es cualitativo de tipo descriptivo. A partir de la revisión bibliográfica sobre los programas alimentarios y entrevistas en profundidad a técnicos y profesionales de la jurisdicción municipal, provincial y nacional se construye el puzzle de la intervención alimentaria en el periodo en estudio. Entre los resultados se observa que las nuevas medidas no se implementaron de manera integral y coexistieron en la administración pública elementos incompatibles en términos teóricos pero que conviven en la práctica. Las condiciones de desregulación y descentralización impactaron en la fragmentación de las políticas alimentarias, el Estado empresario trasladó su intervención compensatoria sobre el problema alimentario hacia una compensación al capital que garantiza el dinamismo del mercado. También predominan las estrategias de autorresponsabilidad y financiamiento de proyectos comunitarios en detrimento de los procedimientos burocráticos.
\end{abstract}

Palabras clave: administración pública - burocracia - gerencia pública - nueva gobernanza programas alimentarios

\begin{abstract}
This paper aims to observe public administration technicians and professionals' perceptions of the governance, public management and bureaucratic models for the management and implementation of food programs between 1983 and 2018 in Argentina. The different administration models become tangible in the know-how practices of those who have designed, managed and implemented these programs, exhibiting tensions between politics and administration. This paper also intends to identify ruptures and continuities in the administration models in order to understand the complexity of the public policy 'making' function in modern democracy. This is a qualitative, descriptive study. Based on food programs literature review and in depth interviews with technicians and professionals at the municipal, provincial and national levels, we put together the puzzle of food intervention in the period
\end{abstract}

${ }^{1}$ (CONICET-UNMDP; CIES) mvsordini@hotmail.com.ar Mar del Plata, Argentina 
Administración burocrática, de gerencia pública y gobernanza en los programas alimentarios de Argentina desde 1983| María Victoria Sordini

under study. The results show that new measures were not implemented comprehensively and that some theoretically incompatible elements managed to actually coexist in public administration. The deregulation and decentralization conditions impacted on the fragmentation of food policies, the public management moved its compensatory intervention on the food problem towards a compensation to capital that guarantees the dynamism of the market. Self-responsibility strategies and financing of community projects are also predominant to the detriment of bureaucratic procedures.

Key words: public administration - bureaucracy - public management - new governance - food programs

\section{Introducción}

En la Argentina desde los años setenta se configuraron nuevas complejidades en las relaciones sociales y politicas a partir del desplazamiento de la acción reguladora del Estado por la liberalización de los mercados. La inestabilidad macroeconómica y el estancamiento productivo impactaron en el aumento del desempleo como condición inherente y vital del modelo de acumulación, siendo el principal desencadenante de las condiciones de pobreza y hambre en los años posteriores (GRASSI, 2003; BECCARIA Y VINOCUR, 1992).

En los años setenta la administración pública dejo de tener un papel central en la producción de bienes y servicios, disminuyó su intervención en la regulación económica y en su capacidad de garantizar derechos sociales (BLUTMAN, 2016). El Estado comenzó a ser observado, tanto desde el capital trasnacional como desde el interior del propio Estado, como un obstáculo para la dinámica de acumulación (MATTOS, 1989). En este contexto emergieron diversas y sucesivas reformas sobre el Estado y la administración pública bajo la modalidad de nuevo gerenciamiento público, reformas de primera y segunda generación, privatización, descentralización y desregulaciones.

Estas prácticas politicas protagonizaron el fin del siglo $\mathrm{XX} \mathrm{y}$ persistieron en el siglo XXI. Los cambios no fueron logrados en su totalidad, la administración pública delego parcialmente tareas al mercado, a la sociedad civil y al ámbito estatal subnacional. El proyecto de modernización 
Administración burocrática, de gerencia pública y gobernanza en los programas alimentarios de Argentina desde 1983| María Victoria Sordini

del Estado, como continuidad del Plan de Modernización, busco fortalecer la gestión del sector público con mayor participación de la sociedad civil. Se destacó la calidad institucional, con transparencia en el acceso a la información, centralidad en el ciudadano, gestión por resultados y objetivos, gestión de recursos humanos, planeamiento estratégico, gobierno electrónico, etc. (BLUTMAN, 2016). Después de la primera década del siglo XXI emergieron algunos matices en un tercer estadio de modernización del Estado con un plan de tecnología y gobierno digital, gestión integral de recursos humanos, gobierno abierto e innovación publica y estrategias de país digital como nexos entre los diferentes niveles de administración gubernamental.

Durante todo el periodo las nuevas medidas no se implementaron de manera integral y fueron coexistiendo en la administración pública elementos incompatibles en términos teóricos pero que conviven en la práctica. El objetivo de este trabajo es observar la percepción de los técnicos y profesionales de la administración pública sobre el modelo burocrático, de gerencia pública y de gobernanza para la gestión e implementación de los programas alimentarios entre 1983 y 2018 en Argentina. Los diversos modelos de administración se cristalizan en las prácticas del hacer de los técnicos y profesionales que diseñaron, gestionaron e implementaron los programas denotando las tensiones que se generan entre el Estado y la Administración Pública, la política y la administración y, la reforma del Estado y reforma de la administración.

El propósito de este trabajo es comprender el rol de la administración pública en la elaboración de políticas alimentarias en los gobiernos democráticos contemporáneos. En tanto la burocracia es una institución crucial en la formulación y ejecución de las políticas (OSZLAK, 2006), reconocer las rupturas y continuidades del modelo burocrático, de gerencia pública y de gobernanza contribuirá a comprender la complejidad del oficio de "hacer" políticas públicas en la democracia contemporánea en Argentina. 
Administración burocrática, de gerencia pública y gobernanza en los programas alimentarios de Argentina desde 1983| María Victoria Sordini

El diseño del estudio es cualitativo de tipo descriptivo (DENZIN Y LINCOLN, 1994). Para responder al objetivo se implementó la técnica de entrevista en profundidad semi-estructurada porque en el transcurso de la misma las personas construyen su mundo de significaciones de modo progresivo y continuo (OXMAN, 1998; MARRADI, ARCHENTI Y PIOVANI, 2007) en relación a las prácticas del saber-hacer políticas públicas.

Se implementó el muestreo teórico siguiendo los lineamientos de la teoría fundamentada (STRAUSS Y CORBIN, 2002) con la técnica de bola de nieve a través de tres redes de contacto en simultáneo con la finalidad de evitar sesgos, atribuirle validez al estudio y de garantizar la heterogeneidad (SCRIBANO, 2008). Se realizaron veintidos entrevistas a técnicos y profesionales que trabajaron, trabajan o son jubilados de la administración pública e intervinieron en programas alimentarios entre 1983 y 2018 del ámbito municipal en el Partido de General Pueyrredón, del ámbito provincial en la ciudad de La Plata, capital de la provincia de Buenos Aires, y del ámbito nacional en la Ciudad Autónoma de Buenos Aires entre los años 2015 y 2017.

El análisis se desarrolla durante todo el proceso de investigación, ya que se trata de una actividad reflexiva que influye en el registro, la redacción, el re-diseño de los instrumentos de observación y el registro de datos adicionales (COFFEY Y ATKINSON, 2003). La entrada al campo en el ámbito gubernamental implicó diversas estrategias para el contacto inicial con las personas técnicas y profesionales. Las personas que en el momento de la investigación se desempeñan en la gestión pública fueron contactadas correo electrónico institucional o teléfono de su lugar de trabajo. Quienes ya no cumplen funciones en el aparato estatal fueron contactadas por correo electrónico o teléfono personal ${ }^{2}$.

La estrategia argumentativa es la siguiente: a) se describirá la cuestión alimentaria como cuestión social; b)se describirá el rol de la

\footnotetext{
2 Para ampliar aspectos metodológicos sobre la implementación de la técnica de entrevista en profundidad en el ámbito de la gestión pública ver (SORDINI, 2018)
} 
Administración burocrática, de gerencia pública y gobernanza en los programas alimentarios de Argentina desde 1983| María Victoria Sordini

burocracia y las tenciones entre lo político y lo administrativo; c) se detallara el rol del modelo de administración de gerencia pública y se profundizará en la descentralización y la fragmentación de las políticas, la focalización de las políticas sociales, la desregulación y la precariedad laboral y el rol del estado empresario en la concepción de los destinatarios de los programas en tanto consumidores; d) se describirá la nueva gobernanza en las políticas alimentarias; finalmente, e) se resumirán consideraciones finales.

\section{I.La cuestión alimentaria como cuestión social}

La igualdad ciudadana y el derecho a la alimentación esta reñidos por la desigualdad económica. En esta tensión aparece la intervención estatal sobre la cuestión social mediante las politicas sociales que señalan diversas alianzas de clase mediante los modos en que se reparte la producción del bienestar entre el Estado, el mercado y las familias (ESPING ANDERSEN, 2000). La política social está ligada de forma recursiva a la estructura social, en tanto surge de esta y configura los procesos de estructuración social que impactan sobre las desigualdades. La politica social no solo compensa las fisuras del modelo de acumulación sino, también puede constituir, aumentar y reproducir las desigualdades sociales (ADELANTADO, et al., 1998).

Las condiciones de hambre y malnutrición en la pobreza es síntoma de la interacción entre el mercado, el Estado y las estrategias de subsistencia de los hogares (GRASSI, HINTZE Y NEUFELD, 1994; AGUIRRE, 2005). La crisis alimentaria se relaciona a las modalidades de reproducción del modelo de acumulación vigente a partir de su estrecha vinculación con las características del sistema agroalimentario, la inserción de la economía nacional en el sistema internacional, la influencia del modelo global de acumulación en la economía nacional, el sistema de distribución del ingreso que regula la reproducción de la fuerza de trabajo y la relación precio de alimentos-capacidad adquisitiva (GRASSI, ET.AL, 1994).

Un Estado nacional emerge y se desarrolla cuando demuestra su capacidad de resolver conflictos sociales y de garantizar la creación de un 
Administración burocrática, de gerencia pública y gobernanza en los programas alimentarios de Argentina desde 1983| María Victoria Sordini

modo de producción capitalista y el bienestar de la población en dicha formación social (OSZLAK, 2006). En tanto la igualdad ciudadana nunca es completa entra en tensión con las desigualdades económicas; ambas constituyen el nodo central de los dilemas de la gobernabilidad (IVO, 2005). La agenda estatal se compone por la gobernabilidad, para garantizar el orden social mediante el desarrollo, el progreso de la sociedad y la equidad mediante la atención de la cuestión social. Estos elementos aparecen en tensión permanente en los Estados capitalistas porque son incapaces de conciliar las condiciones de gobernabilidad democrática, el crecimiento sostenible y la distribución equitativa del ingreso, la riqueza y las oportunidades (OSZLAK, 2006).

La cuestión alimentaria, en tanto cuestión social, es un pilar de la estructura estatal. Entre los elementos esenciales para la creación de un Estado se encuentra el control del abastecimiento de alimentos, como también la selección de organizaciones de las fuerzas armadas, la tributación, la vigilancia policial, la formación de personal técnico. Estos elementos definen la fortaleza o debilidad de un Estado, su grado de centralidad o des centralidad, de estabilidad o inestabilidad (TILLY, 1975).

Desde 1983, en la transición a la democracia, se inaugura un periodo de sucesivos programas alimentarios asistenciales y masivos en su cobertura. El Plan Alimentario Nacional (en adelante PAN), si bien fue concebido como un programa de emergencia por dos años hasta que el crecimiento y la democracia rindieran sus frutos, fue extendido por el presidente Raúl Alfonsín hasta el fin de su mandato. Desde alli todas las administraciones que siguieron continuaron con la implementación planes alimentarios de manera ininterrumpida (BRITOS, ET.AL, 2003; CORTES, KESSLER, 2013). La vigencia permanente de programas alimentarios, focalizados en la pobreza y masivos en los alcances de su cobertura (DE SENA, 2011), que intervienen en tres generaciones de destinatarios (HALPERIN, ET AL, 2011) señala que el problema alimentario no se revierte. La asistencia alimentaria aparece como estrategia institucionalizada que 
Administración burocrática, de gerencia pública y gobernanza en los programas alimentarios de Argentina desde 1983| María Victoria Sordini

responde a la disponibilidad social de los cuerpos sin que ello suponga una subversión del orden imperante (CERVIO, 2017).

En las áreas urbanas, la accesibilidad a los alimentos depende fundamentalmente del mercado y del Estado (GRASSI, HINTZE, NEUFELD, 1994; AGUIRRE, 2005). La capacidad de compra se relaciona con los precios de los alimentos y con los ingresos disponibles sobre los cuales incide el Estado a través de las políticas públicas. Las políticas alimentarias intervienen sobre las necesidades y demandas sociales que constituyen a la cuestión social y, consolidan los contornos de lo que el Estado delimita como problema alimentario (GRASSI, 2003). Su arbitraje plasma las modalidades de responder a la cuestión instalando los límites de su acción y las condiciones de sus destinatarios.

\section{I.El rol de la burocracia}

Para comprender la complejidad y el sentido de las políticas públicas en las democracias contemporáneas es pertinente comprender las organizaciones y redes que desarrollan esas políticas (PETERS, 1993), porque los múltiples actores de la administración pública hacen a las políticas, entonces, las burocracias hacen políticas públicas (OSZLAK, 2006). Conocer las percepciones de los técnicos y profesionales sobre el diseño, gestión e implementación de los programas alimentarios en los que participaron permitirá pensar la relación entre burocracia y políticas públicas.

En el contexto de transición a la democracia, finalizada la última dictadura militar de Argentina, en 1983, el poder ejecutivo nacional asumió el compromiso de garantizar el derecho a la alimentación señalando que la democracia sería una "ficción" si permite "cuerpos y mentes apagadas por la falta de alimentos"3. En la historia de los programas alimentarios

\footnotetext{
3 Fundamentación del proyecto de ley presentado por la Presidencia de la Nación al Congreso Nacional, 1983. La Presidencia de la Nación envió al Congreso de la Nación un proyecto de ley, sancionado ley $\mathrm{N}^{\circ} 23.056$ el 15 de marzo de 1984, que la faculta a realizar acciones destinadas a
} 
Administración burocrática, de gerencia pública y gobernanza en los programas alimentarios de Argentina desde 1983| María Victoria Sordini

contemporáneos el PAN representa un hito fundacional. En primer lugar por la magnitud de su alcance ya que en el momento de su mayor cobertura, en 1987, repartió 1,37 millones de cajas de alimentos mensuales a 1,34 millones de familias en todo el país, aproximadamente el $19 \%$ de la población total (Coordinación Técnica PAN-MSyAS citado en GRASSI, ET.AL., 1994).

El objetivo general del PAN fue complementar la alimentación de familias pobres y especialmente de los grupos más vulnerables mediante la entrega de alimentos. La localización de los destinatarios partió de la elaboración de un "Mapa de Emergencia Social" con base en los datos de vivienda con distinto grado de precariedad y educación del censo de 1980 . La administración del PAN fue altamente centralizada, el Gobierno Nacional gestionaba el embalaje de las cajas de alimentos en las ciudades de Buenos Aires y en Entre Ríos para ser distribuidas en todas las provincias. Los alimentos se adquirian por licitación pública de precios; el agente comprador fue la Junta Nacional de Granos puesto que esa entidad autárquica disponía de una flexibilidad que permitía efectuar las licitaciones con la rapidez que el programa requería. Si las mismas licitaciones hubiesen pasado por el Ministerio de Salud y Acción Social hubieran requerido un mínimo de seis meses mientras que a través de aquel organismo operaron en tres meses (AGUIRRE, 1990).

El PAN se diseñó en enero de 1984, la ley que lo regularizó se sancionó en marzo de 1984 y la primera entrega se realizó en mayo de ese año (AGUIRRE, 1990). La eficiencia y efectividad de la productividad burocrática se relaciona al grado de éxito con que el aparato burocrático alcanza los objetivos y políticas que justifican su existencia, sin embargo, esos logros dependen de una combinación compleja de circunstancias históricas e idiosincrásicas (OSZLAK, 2006). En este sentido se subraya el carácter de emergencia alimentaria, en un contexto de transición a la democracia, de

enfrentar la crítica situación de deficiencia alimentaria aguda de la población más vulnerable y de pobreza extrema. 
Administración burocrática, de gerencia pública y gobernanza en los programas alimentarios de Argentina desde 1983| María Victoria Sordini

una sociedad abanderada por la reivindicación de los derechos humanos y los programas sociales de asistencia masiva.

El equipo de planificación sacamos a la calle en cinco meses un programa que entrego el primer año 1 millón 400 mil cajas. Hicimos primero la planificación de la logística, la planificación del tipo de población a la que queríamos llegar. [Técnica de Gestión nacional]

De esta manera se ilustra como "la principal fuerza motor del gobierno y las políticas no se encuentra en los parlamentos y los funcionarios políticos sino en el servicio civil de carrera" (PETERS, 1993, p. 70) que han puesto en marcha y materializado la respuesta al problema alimentario que se propuso en la campaña electoral. Con la democracia "se come, se cura y se educa" fue el discurso con el que el presidente Raúl Alfonsín ganó la elección. Como afirma el autor, "si funciona la democracia, entonces las políticas adoptadas por un gobierno tienen que parecerse, en alguna medida, a las políticas que los electores pensaron que estaban “comprando" en la elección"(PETERS, 1993, p. 68). En este sentido, la implementación del PAN fue bandera de la intervención de la gestión del presidente Raúl Alfonsín porque inicio y finalizó en su gestión. Sin embargo, la evaluación de la política mostró algunas tensiones entre lo técnicoburocrático y lo político, a saber:

\begin{abstract}
Después de haber evaluado en base a ciertos criterios la adecuación de la implementación del PAN respecto a sus objetivos (...) podiamos concluir que tenía una efectividad del 65\%. ¡Les agarro un ataque de caspa! (en referencia al poder ejecutivo) Agarraron el informe le metieron un sello rojo que decía: secreto, secreto de Estado. Y yo decía "¿Cómo va a ser una estadística de un programa de alimentación secreto de Estado?” (...) Son esos programas que son bandera de una gestión....tenian que ser el 100\% no les gusto.... ¿qué vamos a hacer? La lógica política es distinta a la lógica técnica (...) Estoy tratando de utilizar los datos que tengo para hacer una construcción lo más realista posible. Porque una evaluación te permite modificar las cosas y mejorarlas. Y ese era un programa en especial que cumplia la palabra de un presidente. El pan estaba absolutamente asociado a Alfonsín. [Técnica de Gestión Nacional]
\end{abstract}

Si bien Rose (citado en PETERS, 1993) afirma que la burocracia pública significa un impedimento para que los funcionarios electos proporcionen al público un tipo particular de gobierno, aquí la tensión entre politica y administración aparece en torno al paradigma de la evaluación. 
Administración burocrática, de gerencia pública y gobernanza en los programas alimentarios de Argentina desde 1983| María Victoria Sordini

Desde la administración burocrática-técnica el PAN alcanzó un 65\% de efectividad y ello demuestra el cumplimiento de la palabra del presidente para la percepción de los técnicos. No obstante, la decisión política censuró los resultados de la evaluación.

Mientras en algunas intervenciones la base electoral legitima la decisión política que pretende una coherencia entre las propuestas de campaña presidencial, la implementación de la política pública y su evaluación, en otras intervenciones, el dominio de la autoridad de decisión lo controla la burocracia. Por ejemplo, el Programa Materno Infantil se implementa en Argentina desde 1936 con el objetivo de realizar promoción y atención de la salud universal de madres, niños y adolescentes mediante normas de atención a la salud, asistencia técnica y capacitación en las áreas de maternidad e infancia, el suministro de medicamento, e insumos básicos a centros de salud y la complementación alimentaria a embarazadas y niños con dos kilos mensuales de leche en polvo. La trayectoria de su implementación con cobertura de alcance nacional trasciende a los sucesivos gobiernos que ocuparon el poder ejecutivo. El método de ejecución subraya la centralidad de una administración que conoce cómo llevar adelante el programa. En las percepciones de los técnicos sobre el saberhacer de la implementación de la política se cristaliza la acumulación de poder y autoridad en de dominio burocrático.

\footnotetext{
Al principio se trató a implementar la leche de acuerdo a criterios técnicos y no políticos, ipequeño detalle! Generando por ejemplo, un índice de reparto de la leche que fuera técnico y no político. Entonces, este gobernador es del mismo color que mi partido entones le doy más y este es de otro color le doy menos. ¡No!. Los pibes no tienen la culpa [Técnico de Gestión Nacional]
}

Aquí el servicio civil interviene como un "instrumento obediente e imparcial de soberanía estatal, y un intérprete e implementador de la ley y de las politicas públicas" (RESTREPO MEDINA, 2009, p. 169). Este estatus imparcial del interés público representa la estabilidad y la continuidad tanto del servicio civil como de un programa alimentario de largo aliento. En esta arista del análisis el modelo de administración tradicional, racional y 
Administración burocrática, de gerencia pública y gobernanza en los programas alimentarios de Argentina desde 1983| María Victoria Sordini

normatizado proyecta una separación de la burocracia respecto de la politica a fin de disminuir la corrupción.

Sin embargo, "la burocracia estatal no es el resultado de un proceso racional de diferenciación estructural y especialización funcional, ni su desarrollo sigue un diseño planificado y coherente" (OSZLAK, 2006, p. 2). La burocracia se constituye en un sistema híbrido, con contradicciones, con recorridos sinuosos, erráticos y vestigios de sucesivas estrategias de acción política. Por ejemplo, al tratarse de un país federal, la autonomía que adquieren los gobiernos provinciales y municipales implica la implementación de programas alimentarios que coinciden en sus objetivos, modalidades de prestación y población objetivo.

\section{I.La Gerencia Pública}

Los ejes de la transformación estructural del Estado fueron cambios en la organización y gestión de funciones mediante la descentralización, privatización, desregulación, readecuación de los recursos humanos, la tercerización de los servicios de apoyo, desburocratización y la orientación de la gestión hacia objetivos (RESTREPO MEDINA, 2009).

Por un lado, el Estado nacional desplaza sus responsabilidades de gestión hacia las provincias, por el otro, permite la influencia en la delimitación, definición y modos de abordaje de la problemática social de los Organismos de Crédito Internacional. Desde los años ochenta, las reformas en el diseño de las políticas sociales se han fundamentado bajo el argumento de optimizar la eficiencia para estimular la equidad (SOJO, 1990). Bajo el velo de reducir la pobreza de modo más efectivo y a menor costo se condiciono el financiamiento de las políticas sociales a la concentración del gasto público en determinados sectores sociales (DE SENA, 2011). Entonces, en el marco de políticas privatizadoras, se implementaron programas sociales en las poblaciones más vulnerables de modo selectivo y se eliminaron las intervenciones universales. 
Administración burocrática, de gerencia pública y gobernanza en los programas alimentarios de Argentina desde 1983| María Victoria Sordini

Las tendencias de la gerencia pública también se proponen terminar con las ineficiencias y las rigideces de la burocracia mediante la desestimación de numerosas reglas. Para ello, se implementó la reducción del gasto público, la reducción de personal y la actividad de Estado a través de medidas de privatización (RESTREPO MEDINA, 2009). Durante los años noventa, en los programas alimentarios se suprimieron técnicas y procedimientos mientras se conservaban modalidades de logística, distribución, y entregas de alimentos secos emblemáticas para el modelo de administración burocrática.

En los primeros años del nuevo milenio se incorporó en los programas alimentarios la modalidad de transferencias de ingreso. Así se reemplazó la entrega directa de alimentos por la bancarización para la compra de los mismos mediante una tarjeta de débito para usar en el mercado. En este contexto el Nuevo Proyecto de Modernización estatal despliega una mirada gerencialista que retoma elementos de gestión del sector privado y, otra mirada de una nueva economía institucional que se enfoca en la respuesta ciudadana, la elección del usuario, la transparencia del trabajo para un consumidor (BLUTMAN, 2016). Entre los principales ejes de la transformación estructural del Estado y de su administración se destaca la privatización, entendida como el traspaso desde el sector público a la empresa privada de la propiedad de empresas y de la titularidad de su actividad. Para aplicar esta estrategia de incorporación del mercado en los asuntos públicos se redujo el gasto público, se disminuyó el volumen orgánico y la actividad del Estado.

Entonces, la focalización de las políticas sociales, en detrimento de las intervenciones universales, se instaló en la administración pública desde los años ochenta. Las estrategias de desregulación, descentralización y desprocedimentalización, propios de la lógica empresarial, permearon las porosidades del modelo burocrático durante los años noventa. Estas modificaciones propiciaron un escenario de desregulación y precarización laboral en los técnicos y profesionales de la gestión pública. Durante el siglo 
Administración burocrática, de gerencia pública y gobernanza en los programas alimentarios de Argentina desde 1983| María Victoria Sordini

XXI cobro protagonismo el rol del mercado y la bancarización en las intervenciones del problema alimentario. Estos aspectos se profundizará en los siguientes apartados.

\section{I Descentralización y fragmentación de las políticas}

La descentralización implicó el desplazamiento de responsabilidades a las provincias funciones que hasta el momento gestionaba y financiaba el Estado nacional. Diversas intervenciones alimentarias vieron desplegados sus niveles de gestión y ello generó conflictos en la implementación de los programas en el territorio, o bien, desconocimiento de la existencia de distintas intervenciones según los niveles de dependencia gubernamental generando una matriz fragmentada de la politica alimentaria.

La creación del Fondo POSOCO-PROSONU, en los años ochenta, se realizó para para descentralizar y trasferir a las provincias la responsabilidad sobre los comedores escolares (financiados por parte del gobierno nacional a través del PROSONU) y sobre políticas asistenciales (mediante el POSOCO). Se dispuso la transferencia de instituciones educativas y del personal dedicado a esta función a la instancia provincial mediante la ley $\mathrm{N}^{\circ}$ 24.049. A partir de 1992 se transfieren recursos a las jurisdicciones vía coparticipación con el objeto de que sean destinados a la planificación y ejecución de estas líneas de acción (IERULLO, 2010).

Desde 1990 se implementa el Proyecto Integrado Promoción de la Autoproducción de Alimentos (en adelante ProHuerta) con el objetivo de mejorar la seguridad alimentaria aumentando la disponibilidad, accesibilidad y variedad de alimentos, mediante la autoproducción de alimentos frescos que complementen sus necesidades alimentarias, en huertas y granjas con enfoque agroecológico, de acuerdo a las particularidades y costumbres de cada región. El programa tiene un grado de descentralización medio porque es financiado por presupuesto nacional y estructura su implementación mediante agentes del Instituto Nacional de Tecnología Agropecuaria en cada distrito municipal (VINOCUR Y HALPERIN, 2004). De manera paralela, en el Municipio de General Pueyrredón, desde 
Administración burocrática, de gerencia pública y gobernanza en los programas alimentarios de Argentina desde 1983| María Victoria Sordini

1990 se implementa el Programa de desarrollo alimentario integral (PRODAI) mediante el Programa Municipal de Huertas que tiene objetivo de implementar huertas escolares y estimular a las familias a desarrollar una huerta en la casa. Ambos programas, vigentes en la actualidad, superponen sus tareas y recursos con tensiones que dialogan en sus prácticas, en general, y en la implementación territorial, en particular.

\footnotetext{
Nosotros les dijimos -podemos trabajar juntos- y ellos -nosotros nos encargamos solo de las huertas municipales no vamos a los barrios, no vamos- Entonces, o trabajamos integrados o no nos pisamos los callos...En realidad, nunca hubo un acuerdo, nunca hubo un acuerdo de la municipalidad de trabajar juntos. [Técnica de Gestión nacional]
}

La implementación de ambos programas no se realizó de modo integral sino de manera desarticulada y fragmentada, aunque, desde las percepciones de los técnicos la complementariedad lograda fue dividir el territorio para no superponer la intervención. Como sostiene Oszlak, debido al "fraccionamiento burocrático resultante de la descentralización funcional y la autonomización, la coordinación de actividades entre unidades organizacionales se torna, a menudo, innecesaria o imposible" (2006, p. 11). Mientras la población objetivo del Programa Municipal de Huertas son escuelas y jardines municipales, ProHuerta se focaliza en los hogares urbanos y rurales con Necesidades Básicas Insatisfechas y/o bajo la Línea de Pobreza (huertas familiares); los niños de escuelas localizadas en áreas deprimidas, marginales o rurales dispersas (huertas escolares); y, ancianos, jubilados, discapacitados, drogadictos, enfermos y encarcelados, que cultivan huertas comunitarias con función terapéutica (huertas comunitarias institucionales) (VINOCUR Y HALPERIN, 2004). Las modalidades de intervención de ambos programas se fundamentan en el asesoramiento técnico para desarrollar huertas. Desde las percepciones de los técnicos la imposibilidad de coordinación de las actividades en sus unidades organizacionales se fundamenta en que sus intervenciones son similares.

Llevar el mensaje de ellos [se refiere a los técnicos de Prohuerta] que es el mismo que el nuestro. Que te digan que son de ProHuerta o sos de la 
Administración burocrática, de gerencia pública y gobernanza en los programas alimentarios de Argentina desde 1983| María Victoria Sordini

municipalidad para vos te da igual porque el mensaje es el mismo [Gestión municipal]

En tanto el modo de responder al problema alimentario es el mismo para las personas que reciben la prestación se relativiza la dependencia jurisdiccional de la intervención, como asi también sus objetivos y prestaciones. De esta manera se sacraliza la fragmentación, desarticulación, repetición de objetivos, superposición territorial de intervenciones, focalización en la misma población de la intervención alimentaria como manera de dar respuesta a la cuestión alimentaria.

La fragmentación se reitera en los programas alimentarios que comparten objetivos similares, modalidades de prestación parecidas y destinatarios de sectores sociales con bajos ingresos. Los técnicos y profesionales que gestionan los programas desconocen la simultaneidad de intervenciones que se implementan desde otras jurisdicciones y que complementan las estrategias de reproducción de la vida y de las condiciones de vida de los mismos hogares.

\footnotetext{
En provincia no sé, en provincia de Bs. As. No tengo la menor idea porque no trabaje en provincia. Si existía o no el más vida en ese momento no sé. [Técnico de Gestión nacional]

En los 90 una de las particularidades era que mi programa no se juntaba con el tuyo. [Técnica de Gestión nacional]

Cada programa tiene sus datos, no los comparte con nadie...No hay en el país una base de datos que diga quién es hijo de quien... son fragmentados porque en los programas atendes a una población en particular [Técnico de Gestión nacional]
}

La intervención alimentaria tiene un sentido fragmentario que se naturaliza en el desconocimiento por parte de los técnicos de otros programas y en la desarticulación de los recursos y de las bases de datos de destinatarios. Esta modalidad de trabajo estructura los esquemas de visión y clasificación de los técnicos y profesionales que en sus trayectorias administrativas gestionan estas intervenciones. Así también, se naturaliza la vigencia permanente y simultánea de programas alimentarios que, sin embargo, denota que el problema alimentario no se revierte.

Estas tensiones se manifiestan en los técnicos y profesionales que gestionan las intervenciones al diferenciar su trabajo en el territorio del trabajo de secretarios, funcionarios $y$ decisores políticos que cobran 
Administración burocrática, de gerencia pública y gobernanza en los programas alimentarios de Argentina desde 1983| María Victoria Sordini

injerencia en la ejecución de las políticas. La proximidad con el territorio influye en diferentes dimensiones de la vida organizacional, en tanto el verticalismo de "bajar a territorio" posicionando y definiendo el sentido de las prácticas de manera relacional se cristaliza en la distancia-proximidad entre los funcionario provinciales que monitorean los programas y los técnicos que los implementan en el territorio del distrito municipal (PERELMITER, 2016). Siguiendo a la autora, el encuentro burocrático se establecía en términos de artificialidad en la interacción.

\footnotetext{
La gente, de la provincia no conoce nada, vienen para la foto...los tipos vienen...dan el discurso...y se vaaaaan!! No se quedan a mirar qué están trabajando y cómo se está trabajando. [Técnica de Gestión Municipal] Vienen programas que vienen desde el escritorio, cuando los escriben parece que van a ayudar y al final te complican, te barren la cancha mal [Técnica de Gestión municipal]
}

Las miradas de los técnicos y profesionales sobre el saber-hacer de las políticas públicas que gestionan e implementan legitiman la autoridad desde la legalidad, lo procedimental y lo normativo. El modelo burocrático se constituye en un actor social con recursos e intereses técnico-burocráticos que fundamentan ese saber-hacer. Entonces, cuando el enfoque administrativo es hegemónico se desplaza la política que deviene en técnica. Este modelo entra en crisis cuando se reduce la capacidad de financiamiento estatal frente a las demandas sociales, las tensiones ideológicas entre lo gubernamental y lo técnico se profundizan y emerge la productividad del sector privado sobre el sector público, en un contexto de modernización del Estado y de la administración; en este contexto emerge un modelo pos burocrático (RESTREPO MEDINA, 2009).

\subsection{Focalización de las políticas sociales}

Las medidas de focalización en las políticas sociales se enlazaron con las políticas de ajuste y recesión (GRASSI, 2003) bajo el velo de reducir la pobreza de modo más efectivo y a menor costo. Para ello el Estado importaba políticas sociales de atención a la pobreza, desde las medidas prescriptivas 
Administración burocrática, de gerencia pública y gobernanza en los programas alimentarios de Argentina desde 1983| María Victoria Sordini

de los organismos de crédito internacional, sin atender a las idiosincrasias y necesidades propias del Estado en cuestión (CENA, 2014). En este marco de políticas privatizadoras se instalaron programas selectivos, en detrimento de la universalización de las intervenciones, que sugerian políticas y deslegitimaban la voz de los técnicos y profesionales de la gestión.

\begin{abstract}
Venian los técnicos del banco mundial y nos decían " este programa anduvo muy bien en ¡Ghana!" y nosotros le decíamos -pero la Argentina no tiene nada que ver con ¡Ghana!- -no pero anduvo muy bien, acá este...terminamos con la desnutrición infantil- y nosotros le deciamos, -pero nosotros tenemos muy poca desnutrición infantil, nuestro problema creciente es la obesidad- no no en Ghana la desnutrición infantil bajo del $50 \%$ al $25 \%$-....pero nosotros tenemos menos de $2 \%$ no podemos hacer un programa....no te escuchaban...menos los del banco mundial...ellos venían a colocar créditos [Técnica de Gestión nacional]
\end{abstract}

Si bien se implementaron programas "enlatados", con un diseño y modalidad de implementación prescripta por los organismos internacionales sin considerar las particularidades geopolíticas de cada territorio fueron intervenciones apropiadas a los giros en los modelos de administración. La gerencia publica se caracteriza por el énfasis en los resultado y en la medición del desempeño, el monitoreo y la evaluación (RESTREPO MEDINA, 2009). Estos aspectos eran requisitos fundamentales para el otorgamiento de los créditos. Los programas alimentarios financiados por estos organismos deben presentar un diagnóstico al momento de solicitar el crédito, pautar seguimientos periódicos en el transcurso del programa y una evaluación final. Este aspecto completa de significado la distinción entre políticas con presupuesto nacional y políticas con créditos internacionales.

\footnotetext{
La evaluación es una de las cuestiones que adolece la política pública, sobre todo cuando tiene fondos nacionales, porque cuando tiene fondos internacionales por norma el organismo de financiamiento tiene que tener evaluaciones. Antes del desembolso en la que da inicio al crédito, tiene lo que le llaman una evaluación de medio término y tiene una evaluación de cierre, minimamente (...) como es por norma todos los programas con financiamiento tiene un área de monitoreo y seguimiento, necesariamente con un jefe, con un equipo, con evaluaciones. [Técnico Gestión nacional]
}

De esta manera el aparato crediticio de los organismos internacionales estructuraba el ciclo de las politicas públicas en Argentina garantizando diagnósticos, seguimiento y evaluaciones. Elementos que bajo 
Administración burocrática, de gerencia pública y gobernanza en los programas alimentarios de Argentina desde 1983| María Victoria Sordini

el modelo de administración burocrática o bajo el financiamiento nacional padecía de irregularidades que cristalizaron la tensión entre lo administrativo y lo político.

\subsection{Desregulación, desburocratización y precarización laboral}

La mirada peyorativa sobre los procedimientos burocráticos tiñe la complejidad del contexto administrativo en el que los trabajadores, con antigüedad en el modelo burocrático, se encuentran en situaciones de ineficiencia por la ausencia de procedimientos y de gestión. La desprocedimentalización de la administración pública implica la reducción de tareas y procedimientos a la vez que se prescinde de los saberes técnicos. A finales de los años noventa, con el propósito de intervenir sobre la multiplicidad y superposición de programas alimentarios se integraron y unificaron en el programa Unidos: el Programa Alimentario Nutricional Infantil, el Programa Apoyo Solidario a Mayores y el Proyecto Integrado Promoción de la Autoproducción de Alimentos. El objetivo general fue impulsar un aporte a las necesidades alimentarias del hogar, fomentando mecanismos de asistencia, privilegiando el ámbito familiar, el fortalecimiento de las redes solidarias en la comunidad, y apoyando las estrategias de producción y autoconsumo de alimentos (VINOCUR Y HALPERIN, 2004). Las prestaciones del programa incluian un apoyo económico a los grupos solidarios a través de transferencias (bolsones o cajas de alimentos secos), compras comunitarias de alimentos y autoproducción de alimentos. Sin embargo, fue un programa que no tuvo capacidad de gestión, no se materializó y primó la desprocedimentalización. Los técnicos que trabajaban en este programa no tenian tareas.

\footnotetext{
Se fueron [secretarios y funcionarios] sin poder instrumentar eeeh... la caja del Unidos...éramos personas que teníamos diferentes disciplinas que intentábamos medir o pensar qué hacer con algo que no tenía ni prestación ni sistematización, por lo tanto sobrevivimos haciendo nada durante mucho tiempo. [Técnica de Gestión nacional]
}

Otra de las aristas del "achicamiento del Estado" desde una lógica de empresarial fueron la reducción de las estructuras administrativas y de 
Administración burocrática, de gerencia pública y gobernanza en los programas alimentarios de Argentina desde 1983| María Victoria Sordini

personal. Si se prescinde de tareas y saberes técnicos, se prescinde también de trabajadores. La mirada empresaria se cristaliza en la concepción de la fuerza de trabajo como un costo que se debe reducir para optimizar ganancias.

Gana la Alianza, asumen el 10 de diciembre del 99, en enero echan a más del $50 \%$ del equipo técnico ¿eh? Por supuesto que no teníamos recibo de sueldo ni nada, éramos contratados con factura, éramos autónomos, ni siquiera existía la figura de monotributista, autónomos. Echan al 50\% de los laburantes. [Técnico de Gestión nacional]

Aquellas personas que "sobrevivieron" y conservaron su puesto de trabajo lo hicieron en situación de precarización laboral. Además, los técnicos y profesionales se vieron obligados a la improductividad poniendo en tensión los vestigios del modelo burocrático anterior que tienen en sus prácticas de trabajo. Mientras el programa Unidos se proponía la meta de una entrega mensual de alimentos, solo realizó una entrega cada seis meses.

\begin{abstract}
Unidos no logro en un año y algo hacer dos entregas de 250 mil pesos. Porque nosotros (en referencia al programa anterior en el que trabajó: Programa Alimentario Nutricional Infantil) estuvimos cuatro años para poder hacer la compra a granel, el lugar de estibaje, las personas que completaban la caja, comprar la caja, juntar la caja con los alimentos, llevarla a un camión, en ese camión llevarla a un lugar, de ese lugar trasladarlo a 5 o 6 centros de distribución a lo mejor en una región y ahí el andamiaje municipal, de caritas y eso para acercarlo a la gente. Eso se pudo hacer por los cuatro años y sobretodo porque había continuidad en la prestación. Unidos no supo en la gestión, no supo a quién comprarles, cuáles eran los procesos administrativos para la compra, qué logística había que hacer para el material, después que llamaste a una licitación y tardaron 6 meses en entregarte, vos querian 25 productos y tenías 5 ¿Qué hacias? Tenias que seguir esperando. Todas esas cosas que a lo mejor se habian visto como un déficit del Programa Alimentario Nutricional Infantil tenía que ver con un punto de equilibrio entre: recursos materiales, financieros, capacidad de gobernabilidad y...eeh...posibilidad de llegar con productos a todo el país. (Técnica de Gestión Nacional)
\end{abstract}

En esta cita la técnica compara los procedimientos del Programa Alimentario Nutricional Infantil, implementado entre 1995 y 1999, con el programa Unidos, implementado entre 1999-2001. Si bien ambas intervenciones se despliegan en un contexto de modernización del Estado y de implementación de la nueva gerencia pública se observan fuertes vestigios de las prácticas del modelo burocrático que son necesarias, desde la percepción de la trabajadora estatal, para poner en marcha la política, para materializar los objetivos, para hacer politicas públicas. Ambos modelos 
Administración burocrática, de gerencia pública y gobernanza en los programas alimentarios de Argentina desde 1983| María Victoria Sordini

de administración, el burocrático y el empresarial, se mixturan en la práctica.

El otro extremo de la terciarización de los servicios de apoyo se ubica en el trabajo voluntario de cientos de miles de mujeres que implementaron un programa alimentario en todo el territorio provincial. El Plan Mas Vida se implementa desde 1994 con el objetivo de mejorar las condiciones de nutrición, crecimiento y desarrollo de la población materno infantil, fortaleciendo las capacidades de las familias y consolidando las redes sociales (PLAN VIDA, 2000). La gestión es compartida entre el Estado Provincial (Consejo Provincial de la Familia y Desarrollo Humano), la gestión Municipal (equipos de técnicos y profesionales) y una red de voluntariado integrada por las Trabajadoras Vecinales y Comadres, titulares y suplentes, conocidas en el territorio como "Manzaneras". Las prestaciones del Plan Vida se basase basaban en la entrega de un suplemento nutricional de alimentos frescos y secos, que incluía un refuerzo de leche como elemento emblemático de la intervención, también se ofrecía la promoción de la atención en salud de las mujeres embarazadas y la capacitación en asuntos de nutrición, salud y organización comunitaria. Desde 2004 la modalidad de entrega directa de alimentos se reemplaza por la transferencia monetaria de ingreso.

Para formar parte del equipo de Trabajadoras Vecinales se debían cumplir los siguientes requisitos: tener una actitud solidaria reconocida por sus vecinos, acreditar domicilio en el barrio, contar con disponibilidad horaria por la mañana, contar con un lugar físico apropiado para la distribución de los alimentos, y que en el mismo no funciones un comercio. Las trabajadoras vecinales se ocupaban de: confeccionar los listados de beneficiarios, recibir y entregar los alimentos, realizar las rendiciones pertinentes, concurrir a las capacitaciones previstas e interactuar con los programas vigentes en el distrito. Durante las primeras horas de la mañana, las Trabajadoras Vecinales recibian en sus casas los alimentos que eran distribuidos por empresas contratadas por el Estado provincial. Ellas controlaban los productos y distribuían en bolsas las raciones para cada 
Administración burocrática, de gerencia pública y gobernanza en los programas alimentarios de Argentina desde 1983| María Victoria Sordini

destinataria del programa que estaba a su cargo en su manzana del barrio. Las comadres tomaban protagonismo con acciones complementarias en los Centros de Atención Primaria de Salud otorgándole un rol protagónico a los procesos de salud que acompañan todo el desarrollo del embarazo y el crecimiento de los niños.

De acuerdo al paradigma de gerencia publica la incorporación de trabajadoras vecinales mediante los requisitos de demostrar actitud solidaria, vivir en barrio y tener disponibilidad horaria organiza a esos recursos humanos mediante el cumplimiento de los requerimientos de base para su desempeño y guía las tareas mediante los objetivos del programa. Mediante talleres y capacitaciones para trabajadoras vecinales se transfieren herramientas para tomar decisiones en el territorio y vehiculizar la implementación del programa (SORDINI, 2019). De esta manera el Estado de aleja de las reglas rígidas, de los procedimientos formales y de los sistemas uniformes propios de servicio civil tradicional y burocrático.

En este contexto, desde la mirada de los técnicos y profesionales que gestionaron el programa se puede observar como el modelo de gerencia pública y la lectura empresarial respecto a la ejecución de la política clasifica, define y contonea las prácticas y la acción, de sí mismos y de los otros.

\footnotetext{
Una manzanera que era la que ponía su casa, otra que era la que trabajaban en conjunto para que no estuviera ella siempre esclavizada. [Técnica de Gestión Municipal]

Siguen teniendo tareas porque imaginate como hace un municipio como La Matanza para recoger...tendría que tener un ejército de empleados para poder mantener al día aunque sea nada más que la actualización de beneficiarios [Técnica de Gestión Provincial]
}

La reestructuración estatal moldea los sistemas de clasificación de los técnicos y profesionales en tanto se incorporan categorias propias de un modelo de explotación y expropiación de las energias que tiene la finalidad permanente e ininterrumpida de maximizar ganancias. Nombrar a las trabajadoras vecinales como "esclavidazas" da cuenta de las condiciones de precariedad laboral que experimentan atenuada por la nobleza del diseño del programa que implementa duplas de "Trabajadora Vecinal y Comadre" para 
Administración burocrática, de gerencia pública y gobernanza en los programas alimentarios de Argentina desde 1983| María Victoria Sordini

que desarrollen sus tareas en conjunto y para que "no estuviera esclavizada" una persona sola, en tanto se trata de una intervención que se apoya en la actitud solidaria de las mujeres que desempeñan estos roles. Por otro lado, la noción de "tendría que tener un ejército de empleados" de no existir la figura de la trabajadora vecinal que "sigue teniendo tareas" en el territorio da cuenta de la masividad de la figura de "trabajadora vecinal" y la de precarización de su labor. Si bien se nombra como trabajadora y desde los sentidos y significados de los técnicos sus funciones equiparan un ejército de empleados su retribución es una prestación del programa Plan Vida mensual (SORDINI, 2019). A pesar de los giros en la modalidad de prestación que implico el reemplazado de la entrega directa de alimentos por las transferencias de ingresos monetarias la figura de la trabajadora vecinal continua vigente. En la actualidad se ocupa de la gestión de los trámites para habilitar el uso de las tarjetas de débito. Aquí se cristaliza el fortalecimiento de la carrera de la trabajadora vecinal, con más de veinticinco años de actividad en el territorio y cómo el Estado consolido la tercerización de los servicios de apoyo, desburocratizando la administración y orientando su acción al cumplimiento de metas y objetivos.

\subsection{El estado empresario: de ciudadanos a consumidores}

La reforma de Estado de la década de los años ochenta, se encuadra y se determina por el entorno económico de globalización y crisis de financiarización del Estado de bienestar y, un contexto de desocupación y pobreza que profundiza la complejidad de la cuestión social y de su atención mediante las políticas sociales. La interrelación que se plantea entre el mercado, las instituciones de protección social y el modelo de acumulación en la regulación de la desigualdad económica, etaria, étnica, de género, entre otras, se produce mediante la intervención de las políticas sociales. Si bien las instituciones de protección social aparecen disociadas del mercado, en la práctica son inherentes a este, dado que "sin las instituciones nomercantiles de protección social, el mercado no podría estabilizar el régimen 
Administración burocrática, de gerencia pública y gobernanza en los programas alimentarios de Argentina desde 1983| María Victoria Sordini

de acumulación en las sociedades modernas" (GOLDBERG Y LO VUOLO, 2006 , p. 28). A través de las políticas sociales se redistribuyen recursos en la sociedad y se moldean las relaciones sociales que se establecen entre cada esfera permitiendo las condiciones para cambios y permanencias estructurales o la emergencia de nuevos actores y procesos sociales (ADELANTADO ET AL, 2000).

En la trayectoria de programas alimentarios contemporáneos, en 1989 el nuevo gobierno decretó el fin del PAN e implementó el programa "Bono Solidario de Emergencia". Esta decisión ilustra la manera en la que el mercado y el sector privado se "ocupa" del problema alimentario. Para financiar el programa se complementaron los fondos estatales con contribuciones voluntarias que realizaban las empresas como resultado de una campaña solidaria emprendida por un Consejo Nacional. El Congreso sancionó la ley $\mathrm{N}^{\circ} 23.740$ que estableció la creación de una contribución solidaria para el sostenimiento de este plan. Esa contribución se calculaba sobre la base de los ingresos obtenidos en 1988 de las personas físicas y jurídicas (VINOCUR Y HALPERIN, 2004; IERULLO, 2010).

\footnotetext{
Se suponía que era solidario porque iba a redistribuir el dinero que empresarios y...benefactores le dieran al Estado que lo iba a distribuir, es decir, se abría un registro de empresarios...que solidariamente, voluntariamente aportaran miles de millones y el Estado lo iba a distribuir vía los intendentes, los diputados...mediante la estructura del Estado (Técnico de Gestión Nacional)
}

El programa se destinaba a personas que presentasen declaración jurada sobre su situación de emergencia alimentaria ante los gobiernos locales. La distribución de los bonos se haría a través de Consejos Locales de Emergencia. Si bien se proyectó entregar 571.428 chequeras por mes para todo el país solo se hicieron efectivas dos entregas en septiembre de 1989 y en enero de 1990 (VINOCUR Y HALPERIN, 2004; IERULLO, 2010).

Si bien la intervención no prosperó muestra un giro significativo en la modalidad de prestación. Se reemplazó la entrega directa de alimentos, como implementó la caja PAN, por un bono, con valor económico para intercambiar alimentos en el mercado. De esta manera los destinatarios del 
Administración burocrática, de gerencia pública y gobernanza en los programas alimentarios de Argentina desde 1983| María Victoria Sordini

programa adquieren sus alimentos según la oferta del mercado y limitados por el monto disponible de la prestación. El monto de la prestación está condicionado por los aportes voluntarios que realicen los empresarios y por la inestabilidad económica y los problemas inflacionarios de ese contexto histórico El valor del Bono Solidario comenzó siendo el 56,4\% de un sueldo mínimo y siete meses después representaba solo el 6,35\% del mismo (AGUIRRE, 1990).

Aquí es pertinente recuperar algunos datos de la evaluación del PAN en 1989 en la que se comparó el costo de la prestación con los valores de esos productos en el mercado minorista. El informe sostiene que las familias destinatarias del PAN recibieron un subsidio que varió del 8 al 15\% de un sueldo mínimo y que le cubría del 23 al 30\% de sus recomendaciones nutricionales. Además, el informe sostiene que si se hubiera considerado la experiencia internacional de los Food Stamp Program, que se implementaron en la década de 1930 en Estados Unidos, como programa asistencial basado en la entrega de bonos intercambiables por alimentos en el mercado minorista los productos hubiesen costado el doble (AGUIRRE, 1990) porque se empuja al ciudadano a consumir de manera individual frente a los precios del mercado minorista. Sin embargo, la evaluación del PAN se censuró y en el año siguiente se implementó el programa Bono Solidario de Emergencia que replicó el modelo Estadounidense. Años más tarde, esta modalidad de prestación se reactualizó en las transferencias monetarias de ingreso bancarizadas.

A mediados de la década de los años noventa, las estrategias de intervención sobre la población en situación de pobreza se han visto signadas por la emergencia de Programas de Transferencias Condicionadas de Ingreso. Esta modalidad consiste en el otorgamiento de recursos monetarios a las familias que viven en situación de pobreza y tienen hijos/as menores de edad, con la condición de que certifiquen el cumplimiento de conductas asociadas al mejoramiento de sus capacidades humanas, generalmente vinculadas con la educación y la salud de los niños/as del 
Administración burocrática, de gerencia pública y gobernanza en los programas alimentarios de Argentina desde 1983| María Victoria Sordini

hogar (CECCHINI Y MADARIAGA, 2011). Se trata de programas impulsados, evaluados y, en muchos casos, financiados por Organismos Multilaterales de Crédito, cuyos objetivos han perseguido "reducir la pobreza en el corto plazo (mediante el aumento del consumo de las familias pobres, favorecido por las transferencias monetarias) así como en el largo plazo (mediante el fortalecimiento del capital humano de los niños, impulsando las condicionalidades)" (CEPAL/OIT, 2014, p. 14).

En las intervenciones alimentarias las transferencias de ingreso se implementaron en los primeros años del siglo XXI. En el nivel provincial, el Plan Más Vida, que se ejecuta desde 1994, en 2004 reemplazó la entrega directa de un suplemento nutricional en alimentos frescos y secos por la transferencia mensual de U\$S 10 por cada menor de seis años que vive en el hogar. En el nivel municipal, el programa Complemento Alimentario Familiar reemplazó desde 2008 la entrega directa de alimentos a familias en condiciones de vulnerabilidad por una transferencia de ingresos de U\$S 6.

La monetarización y bancarización de las politicas sociales ha sido legitimada bajo el argumento de que eliminaria intermediarios y contrarrestaría prácticas corruptas y clientelares en la implementación de los programas, a la vez que se aduce que presentan un costo menor que las transferencias en especie (CENA, 2014). Esta modalidad descongestiona ampliamente las dinámicas de licitación, logística y distribución de alimentos del anterior modelo burocrático y se reduce el gasto público que ocasiona esa gestión. No solo se terciarizan y descentralizan los servicios provistos por el Estado sino que se materializa un giro en la concepción de las personas destinatarias de estas intervenciones en tanto predomina el rol de consumidor de los destinatarios. El acceso a los alimentos, cada vez más lejos de concebirse- como un derecho, se mercantiliza. En este contexto, la elección de alimentos comienza a limitarse en función de los montos de la prestación, los comercios habilitados para utilizar la tarjeta magnética de débito bancario y la oferta que realiza el mercado. De esta manera el ciudadano/administrado se convirtió en un cliente y la administración obra 
Administración burocrática, de gerencia pública y gobernanza en los programas alimentarios de Argentina desde 1983| María Victoria Sordini

con un enfoque empresarial, de gerencia por objetivos y resultados (RESTREPO MEDINA, 2009).

En este contexto de desburocratización de la administración pública mediante la adopción de prácticas y métodos del sector privado, la orientación al cliente y la percepción del ciudadano como consumidor se complementa con el énfasis en el empoderamiento de los usuarios. Estos programas han sido reivindicados por la autonomía en la elección de los alimentos que adquieren los "usuarios". Sin embargo, esa autonomía se limita a los precios del mercado y los montos de la prestación.

\footnotetext{
Y para aquellas personas que todavia necesitan un complemento, no hay bolsones sino hay tarjetas como la tuya y la mía de Banelco y eso, con la cual se le da plata para que la persona vaya a cualquier supermercado, la pase y compre lo que tiene que comprar. Todavia sigue siendo un monto chiquito, porque hay mucha cobertura. [Técnica de Gestión nacional]
}

Mientras en las prácticas del saber hacer políticas alimentarias se fundamenta el bajo monto de la prestación por la amplia cobertura, se ocluye el problema alimentario como problema de acceso a los alimentos por las condiciones de desigualdad social. El monto de la prestación es decisivo para acceder a determinada cantidad y calidad de alimentos debido a que amplios sectores sociales urbanos no comen lo que quieren o lo que les gustaria comer, sino comen lo que pueden comprar (AGUIRRE, 2005). Sin embargo, sostener que el monto para la compra de alimentos es bajo porque los destinarios son muchos naturaliza la ineficiencia de la prestación, su masividad y desdibuja el rol del Estado como garante del derecho a la alimentación.

A partir de la bancarización de los destinatarios se direccionan las fechas en las que se realizan los consumos, los lugares habilitados para realizar las compras con tarjeta de débito, los productos habilitados para comprar con esas tarjetas, los tipos de productos que componen las ofertas (según la cantidad de productos iguales o segundas marcas) o la calidad de los alimentos de menor costo. Se trata más de un mecanismo de consumo compensatorio al capital (DE SENA Y SCRIBANO, 2014) que de 
Administración burocrática, de gerencia pública y gobernanza en los programas alimentarios de Argentina desde 1983| María Victoria Sordini

compensación a las necesidades alimentarias, en tanto se garantiza el dinamismo económico en determinados espacios (bancos, supermercados, primeras y segundas marcas de alimentos) mientras que en los hogares se ha reforzado el consumo de comidas rendidoras, que dan saciedad y nutren poco (AGUIRRE, 2005).

En la expresión "compran lo que tienen que comprar" con "montos chiquitos" subyace el sentido que se le otorga a la prestación y a los destinatarios/usuarios de la misma. Así como en los años ochenta bajo los criterios de eficiencia y equidad se implementó la "focalización reduccionista" (SOJO, 2007) y el Estado desempeño el rol de atender a las necesidades de los grupos más vulnerables, en el cambio de milenio la nueva gerencia pública implementa programas sociales atravesados por la lógica económica de maximizar ganancias y garantizar efectividad productiva mediante la ecuación costo-beneficio. Desde la mirada de los técnicos la cobertura masiva se vuelve una potencialidad de la distribución del capital, en detrimento del bajo monto de la prestación.

Este giro en las modalidades de prestación alimentaria moldea prácticas alimentarias de preparación y consumo de alimentos, configuran el consumo en determinadas fechas de cobro y lugares habilitados para usar la tarjeta y, modela los cuerpos según la cantidad y calidad de alimentos accesibles en el mercado. Entonces, entre las estrategias domésticas de consumo, los hogares de menores recursos, suplantan densidad nutricional por energía barata, en tantos los productos que se ofrecen a menor precio en el mercado coinciden con alimentos ricos en hidratos de carbono, grasas y azucares y ultraprocesados (AGUIRRE, 2011). Las carencias de nutrientes se ocluyen en los cuerpos fornidos que consumen productos alimenticios pero que nutren poco. Entonces, el problema alimentario se cristaliza en el aumento de la obesidad en la pobreza (AGUIRRE, 2011) y con mayor prevalencia en las mujeres (FAO et al., 2019).

Los programas alimentarios constituyen una política de los cuerpos (SCRIBANO, 2012) en tanto operan como estrategia que garantiza la 
Administración burocrática, de gerencia pública y gobernanza en los programas alimentarios de Argentina desde 1983| María Victoria Sordini

disponibilidad social de los individuos, habilitando o no determinados alimentos, nutrientes y energías mediante sus prestaciones. Los limites energéticos corporales que garantizan los programas alimentarios configuran los límites de las energías sociales sobre las condiciones históricas de reproducción de la población y de la fuerza de trabajo, determinados desarrollos cognitivos, interacciones sociales y trayectoria de clase (DE SENA Y SCRIBANO, 2013). De esta manera la transformación estructural del Estado gira en una dirección que modela la expropiación de las energías de amplios sectores sociales destinatarios de politicas sociales.

Mediante las transferencias de ingreso el Estado delega responsabilidades sociales en el mercado y se limita controlar técnicas gerenciales en la administración pública generando las condiciones para que el ciudadano se convierta en un cliente y la administración actúe con un enfoque empresarial orientada al mercado en un contexto de competencia y privatización (RESTREPO MEDINA, 2009).

\section{I.La gobernanza: los ciudadanos resuelven la cuestión social}

La gobernanza tiene un factor causal crucial en el enlace entre el proceso gerencial y el proceso político-civil que ha caracterizado las reformas institucionales, fiscales, políticas, administrativas y económicas llevadas a cabo con el cambio de siglo. El gobierno obra como un agente de dirección necesario para garantizar la existencia de cooperación y su eficacia, pero que no es suficiente, ya que para gobernar no solamente se requieren los recursos del poder público sino también los de los mercados y las redes sociales (RESTREPO MEDINA, 2009).

Las licitaciones en el Estado nos llevaban a que estuviéramos 2 o 3 meses sin que pudiéramos entregar alimentos, solo resolviendo con lo que podía entregar Cáritas o lo que podía mandar la provincia en víveres. [Técnica de Gestión municipal]

El proceso de gobernanza se estructura institucional y técnicamente a partir de la interlocución de grupos y sectores sociales entre sí con el 
Administración burocrática, de gerencia pública y gobernanza en los programas alimentarios de Argentina desde 1983| María Victoria Sordini

gobierno, reconociendo que el resultado no se logra ni con mando y control gubernamental sobre una sociedad dependiente, ni tampoco con la vigencia de la autorregulación y el mercado o solo por los vínculos de la solidaridad de las organizaciones sociales (RESTREPO MEDINA 2009). La interacción entre los distintos niveles de gobierno y, entre estos, las organizaciones privadas y la sociedad civil requiere de un espacio público deliberativo que retroalimente la confianza en la interdependencia. Esta tarea demanda una reestructuración en las funciones gubernamentales para que los intereses concernidos por el proceso decisional se encuentren simétricamente representados. Por ejemplo, en el MGP en 1997 se implementó el Programa Alimentario Único con la participación del gobierno municipal, provincial y Cáritas ${ }^{4}$.

Desde una perspectiva de democratización de la estructura burocrática se gestan sistemas estandarizados de control y co-gestión de lo público consolidando acuerdos entre el Estado y la Sociedad Civil para garantizar resultados de procesos participativos (ORTIZ SANDOVAL, 2012). En esta clave las organizaciones de la sociedad civil y la responsabilidad social empresaria se han ocupado también de la cuestión alimentaria. Este diálogo se ilustra a través del "banco de alimentos", creado en 2002 con personería jurídica en el edificio de Cáritas Diocesana, que solicita donaciones de alimentos aptos para el consumo a empresas productoras y comercializadoras, a productores agropecuarios y donaciones particulares. También recibe donaciones monetarias para comprar alimentos en supermercados mayoristas, en algunos supermercados existen canastos para la donación voluntaria de los clientes y, en algunos eventos se fija como entrada un alimento no perecedero. Estos recursos se distribuyen en centros de promoción humana, comedores comunitarios, asilos de ancianos, hogares

\footnotetext{
4 Cáritas es una organización dedicada a la pastoral social y a la caridad. En 1956 se creó Cáritas Argentina en la Conferencia Episcopal Argentina, siguiendo los lineamientos de Caritas Internationalis, con el objetivo de "animar y coordinar la obra social y caritativa de la Iglesia, insertada en la pastoral orgánica a través de formas adaptadas al tiempo y las circunstancias, para lograr el desarrollo integral de todo hombre y de todos los hombres, con especial preferencia por las personas y comunidades más marginadas" (CÁRITAS, 2010, p. 7)
} 
Administración burocrática, de gerencia pública y gobernanza en los programas alimentarios de Argentina desde 1983| María Victoria Sordini

de niños y, también las organizaciones de la sociedad civil pueden ir a comprar alimentos a muy bajo costo (CÁRITAS, 2007).

El nodo central del nuevo modelo de gobernanza es la participación ciudadana, la mediación de la administración pública y actores privados que convergen esfuerzos para dar respuesta a la cuestión alimentaria. En esta interacción priman conceptos como transparencia, rendición de cuentas, debido proceso, probidad y eficiencia.

Otra modalidad mediante la cual el Estado legitima la organización colectiva de la emergencia y necesidad de comer es mediante el financiamiento de comedores comunitarios. Desde 1989, en un contexto de fuerte deterioro de los ingresos de amplios sectores sociales, surgieron acciones precarias y espontáneas, autogeneradas por vecinos con una capacidad limitada de ofrecer alimentos mediante ollas populares o comedores comunitarios (VINOCUR Y HALPERIN, 2004). Si bien estas formas de asociación surgieron como prácticas temporarias se consolidaron durante los años noventa como consecuencia de la continuidad y profundización del empobrecimiento y de la implementación de los programas de apoyo a comedores comunitarios que legitimaron a los comedores comunitarios como respuesta al problema alimentarios.

Desde 1995 se implementa el Fondo Participativo de Inversión Social que funciona a partir de un proceso conjunto de organización comunitaria de base, de formulación de proyectos y de ejecución de obras para la mejora y ampliación de servicios alimentarios. Tiene el objetivo de desarrollar capacidades locales de gestión a través de la formulación, gestión y ejecución de proyectos destinados a mejorar las condiciones socioeconómicas de grupos y comunidades en situación de pobreza. Desde 2002 se centra exclusivamente en el financiamiento de proyectos con intervención en la emergencia alimentaria (IERULLO, 2010). A través del Fondo Participativo de Inversión Social, la Secretaría de Desarrollo Social ofrece a las organizaciones comunitarias actividades de asistencia técnica y capacitación, basándose en una metodología participativa de múltiples 
Administración burocrática, de gerencia pública y gobernanza en los programas alimentarios de Argentina desde 1983| María Victoria Sordini

instancias y destinada a garantizar la inclusión de los actores en la toma de decisiones y ejecución del programa. Sin embargo, desde la mirada de los técnicos con amplia trayectoria en la gestión la incorporación de esta modalidad presentó fricciones con su concepción sobre las políticas públicas.

\footnotetext{
Los programas con financiamiento, sobre todo en los 90 , de los programas para capital social, financiaban a ONG. ¿'eso cómo se articula con una política pública? No se articula para nada con una política pública, más bien está en las antípodas de una política pública, por más que se haga desde una unidad ejecutora dentro del ministerio. Entonces esta lógica, digamos, de que la ONG se presenta, concursa y que gane el mejor tiene, desde mi humilde perspectiva tiene, un problema grave vinculado con el fortalecimiento de la política pública. En general el mejor no está nunca demasiado cerca del más pobre [Gestión Nacional]
}

Una vez más se observa cómo las transformaciones en el modelo administrativo avanzan en un camino que prescinde cada vez más de la mirada técnica y profesional en relación al diagnóstico territorial y al diseño de programas alimentarios desde la administración pública. La tarea de formulación de la politica pública es por la que concursan diversas Organizaciones No Gubernamentales y esta modalidad de gestión predomina incluso en la actualidad. De esta manera, la apertura del gobierno a la sociedad civil, permite que la rendición de cuentas y la regulación sean por vigilancia externa. En esta modalidad se trasciende la satisfacción de las demandas de los ciudadanos, sino que se incorpora a los propios ciudadanos en la resolución de las problemáticas de la cuestión social.

\section{Consideraciones finales}

Los modelos de administración han configurado las relaciones sociales en las que se desempeñan los técnicos y profesionales de la gestión pública que ejecutan a las políticas alimentarias, que hacen politicas públicas. En sus percepciones y en sus prácticas del saber-hacer se han configurado una conciencia práctica (GIDDENS, 1995) que permite comprender la estructura social en la que se despliegan las intervenciones alimentarias. Las trayectorias de trabajo de los técnicos y profesionales entrevistados poseen la experiencia de diversos programas alimentarios, en sucesivas gestiones 
Administración burocrática, de gerencia pública y gobernanza en los programas alimentarios de Argentina desde 1983| María Victoria Sordini

gubernamentales con más de diez años de trabajo en la gestión pública. En sus prácticas se ejercita la mirada burocrática, los saberes técnicos, vivenciaron la descentralización y desburocratización, reconfiguraron sus modalidad de trabajo con medidas de privatización estatal, trabajaron hombro a hombro con organizaciones de la sociedad civil y vecinos que implementaron las intervenciones en el territorio, asumieron las indicaciones de los organismos de crédito internacional para la delimitación de los problemas sociales.

La reestructuración de los modelos de administración es atravesada por una fuerte tensión entre lo técnico-burocrático y lo político. Si bien el servicio civil de carrera ha materializado la respuesta al problema alimentario con la gestión de sus tareas en algunas intervenciones predomina lo político sobre lo administrativo. Mientras en el Plan Alimentario Nacional, vigente entre 1984 y 1989, la base electoral legitima la decisión politica, en un contexto de transición a la democracia y altos niveles de empobrecimiento, en el Programa Materno Infantil, vigente desde 1936 a la actualidad, la acumulación de poder y autoridad es de dominio burocrático.

Las condiciones de desregulación y descentralización han impactado en la fragmentación de las políticas alimentarias. La falta de integralidad implica que las personas en situación de necesidad alimentaria sean focalizadas por diversas y múltiples intervenciones que se proponen objetivos similares y prestaciones limitadas. La superposición de tareas y recursos en las distintas jurisdicciones genera tanto tensiones entre los técnicos y profesionales que comparten el trabajo territorial con diferentes programas como, indiferencia y desconocimiento de otras intervenciones similares entre el servicio civil nacional o provincial, que no trabajan en el territorio municipal.

El modelo de gerencia pública se apoyó sobre la desburocratización, la subestimación de procedimientos y reglas administrativas, la implementación de objetivos de eficiencia que guíen la tarea estatal y 
Administración burocrática, de gerencia pública y gobernanza en los programas alimentarios de Argentina desde 1983| María Victoria Sordini

fundamentalmente, en la concepción de los ciudadanos en tanto consumidores. Se delegan al mercado la respuesta a la cuestión alimentaria mediante prestaciones de transferencias de ingresos que empujan al ciudadano a acceder a los alimentos según la oferta que el mercado dispone y limitado por los montos "pequeños" de las transferencias monetarias. De esta manera se suprimen las tareas burocrático-administrativas de logística para la compra de alimentos, distribución y entrega que implican la modalidad de entrega directa de alimento.

Bajo el argumento de que los ciudadanos vivencian mayor autonomía en la elección de sus alimentos en el mercado se expandió esta modalidad de prestación. Sin embargo, las posibilidades de elección de alimento se encuentran limitadas por los montos disponibles y por la oferta del mercado. Como lo señaló la evaluación del Plan Alimentario Nacional en 1989, la centralización del Estado nacional en la logística y distribución de los alimentos garantiza un menor costo de esos alimentos que si cada ciudadano/consumidor los debe adquirir de manera individual en el mercado.

En esta complejidad de relaciones, la intervención compensatoria y asistencialista sobre el problema alimentario en los hogares en condiciones de pobreza se desplaza hacia una compensación y asistencia al capital porque se garantiza el dinamismo del mercado. Se reemplaza la asistencia alimentaria compensatoria por el consumo compensatorio privilegiando el acceso al consumo, la bancarización y la compra de alimentos a un precio minorista en comercios habilitados al débito automático.

Las intervenciones de las políticas sociales moldean los modos en que se estructuran las relaciones sociales y desde alli, configura las maneras de ser, de hacer, de comer. El modelo de gobernanza, por su parte, legitimó la resolución de la cuestión alimentaria por parte de los vecinos, que organizados reciben financiamiento y apoyo técnico para proyectos comunitarios que atienden a la emergencia alimentaria. Estas estrategias se ensamblan en una cinta de moebio en la que aparece y desaparece lo 
Administración burocrática, de gerencia pública y gobernanza en los programas alimentarios de Argentina desde 1983| María Victoria Sordini

individual y lo comunitario, comprar en el mercado minorista con transferencias monetarias reducidas y auto-organizarse con vecinos para enfrentar la necesidad colectiva de comer. Ambas estrategias se apoyan en la autorresponsabilidad de los ciudadanos/consumidores sobre la cuestión alimentaria. En este escenario se generan tensiones en los técnicos y profesionales de los programas alimentarios en relación a las transformaciones que implican la omisión, invisibilización, supresión de las estrategias técnicas y burocráticas para diseñar intervenciones sobre la cuestión alimentaria.

\section{Referencias bibliográficas}

ADELANTADO, José, NOGUERA, José Y RAMBLA, Xavier "El Marco de Análisis: las relaciones complejas entre estructura social y politicas sociales", (pp. 23-62). En Adelantado, José (Comp.) Cambios en el Estado de Bienestar. Politicas Sociales y Desigualdades en España. Barcelona: Editorial Icaria, 2000.

AGUIRRE, Patricia. El Pan "Programa alimentario nacional" Informe sobre su implementación entre los años 1984-1990. Buenos Aires: Desarrollo y Acción Social, 1990.

AGUIRRE, Patricia. Estrategias de consumo: qué comen los argentinos qué comen. Buenos Aires: Mino y Dávila, 2005.

AGUIRRE, Patricia. Reflexiones sobre las nuevas formas del hambre en el siglo XXI: la obesidad de la escasez. Boletin Cientifico Sapiens Research, Vol. 1 (2) 60-64pp, 2011.

BECCARIA, Luis Y VINOCUR, Pablo. "La pobreza del ajuste o el ajuste de la pobreza" Revista Ciencia Hoy Vol. 4 N²1. Pp.16 a 24 General Sarmiento: Universidad Nacional de General Sarmiento, 1992.

BLUTMAN, Gustavo. Buscando armar el rompecabezas de la gestión pública: Argentina en el Siglo XXI (dossier). Revista Estado y Politicas Públicas N ${ }^{\circ}$ 7.PP. 69-81, 2016. 
Administración burocrática, de gerencia pública y gobernanza en los programas alimentarios de Argentina desde 1983| María Victoria Sordini

BRITOS, Sergio, O`DONNELL, Alejandro, UGALDE, Vanina y CLACHEO, Rodrigo. Los programas alimentarios en argentina. Buenos Aires: Cesni, 2003

CÁRITAS. Cáritas Mar del Plata. -memoria y balance 2004-2007. Cáritas, 2007. Disponible en: http://www.caritasmardelplata.org.ar/quienessomos/historia/ Acceso: 18/09/2019

CECCHINI, Simone y MADARIAGA, Aldo. Programas de Transferencias Condicionadas: balance de la experiencia reciente en América Latina y el Caribe. Cepal, Santiago de Chile: Naciones Unidas, 2011. Disponible en: http://www.cepal.org/dds/noticias/paginas/6/28106/protsocnocontr.pdf Acceso: 22/11/2019

CENA, Rebeca. Imagen mundo y régimen de sensibilidad. Un análisis a partir de las políticas sociales de atención a la pobreza implementadas en Argentina. Revista Latinoamericana de Estudios sobre cuerpos, emociones y sociedad. $N^{\circ} 14$. Año 6 . Abril 2014.

CERVIO, Ana. Política alimentaria, pobreza y emociones en la Argentina de los años 80. Entramado, 15(1), 62-77, 2019.

CEPAL/OIT. Coyuntura laboral en América Latina y el Caribe. Los programas de transferencias condicionadas y el mercado laboral. Cepal, Santiago de Chile: Naciones Unidas, 2014. Disponible: http://www.ilo.org/Search5/search.do?searchWhat=programas+de+transfer encias+condicionadas\&locale=es_ES Visto: 25/06/2019

COFFEY, Amanda y ATKINSON, Paul. "Variedades de datos y variedades de análisis." En: Coffey, Aamanda, y Atkinson, Paul (coord.) Encontrar el sentido a los datos cualitativos. Estrategias complementarias de investigación. (Pp.1-30) Medellín: Universidad de Antioquia, 2003

CORTES, Rosalía Y KESSLER, Gabriel. miradas sobre la cuestión social en la Argentina democrática (1983-2013). Cuestiones de Sociologia, No ${ }^{\circ}$. Universidad Nacional de La Plata. Facultad de humanidades y ciencias de la educación. Departamento de Sociología, 2013.

DENZIN, Norman y LINCOLN, Yovana. Handbook of Qualitative Research, Thousand Oaks: Sage Publications, 1994.

DE SENA, A. "Promoción de Microemprendimientos y políticas sociales: ¿Universalidad, Focalización o Masividad?, una discusión no acabada”. En Revista Pensamiento Plural. Año 4 No 8, pp 36-66, 2011.

GRASSI, Estela, HINTZE, Susana Y NEUFELD, María. Políticas sociales, crisis y ajuste. Buenos Aires: Espacio Editorial, 1994. 
Administración burocrática, de gerencia pública y gobernanza en los programas alimentarios de Argentina desde 1983| María Victoria Sordini

ESPING ANDERSEN, Gosta Fundamentos sociales de las economias postindustriales. Barcelona: Ariel, 2000.

FAO, OPS, WFP y UNICEF. Panorama de la seguridad alimentaria y nutricional en América Latina y el Caribe. Santiago: FAO, 2019. Disponible: http://www.fao.org/3/ca6979es/ca6979es.pdf Acceso: 14/12/2019

GOLBERG, Laura Y LO VUOLO, Rubén Falsas promesas: Sistema de previsión social y régimen de acumulación. Buenos Aires: Ciepp, Miño y Dávila, 2006.

GRASSI, Estela Políticas y problemas sociales en la sociedad neoliberal. La otra década infame (I). Buenos Aires: Espacio Editorial, 2003.

HALPERIN WEISBURD, Leopoldo, LABIAGUERRE Juan, DE SENA, Angélica, GONZÁLEZ Marita, HOREN Berta, MÜLLER Guillermo; QUIROGA, Lucila, VILLADEAMIGO, Jose, CHARVAY, Camila, HALPERIN Celina, LABIAGUERRE, Edurne, PUJOL BUCH Y CHAHBENDERIAN, Florencia."Problemas de género en la Argentina del siglo XXI: feminización de la pobreza e inequidad del mercado laboral", Cuadernos del Centro de Estudios sobre Población, Empleo y Desarrollo No.11. Argentina : Facultad de Ciencias Económicas, Universidad de Buenos Aires,2011.

IERULLO, Martín El proceso de consolidación de los programas de asistencia alimentaria en Argentina (1984-2007) En Clemente, Adriana (Coord.) Necesidades sociales y programas alimentarios. Las redes de la pobreza. Buenos Aires; Espacio Editorial., 2010

IVO, Anete "La destitución de lo social: Estado, gobierno y políticas sociales", en Estudios Sociológicos, Vol. 23, No. 68, 2005

MARRADI, Alberto, ARCHENTI, Nelida, \& PIOVANI, Juan. Metodología de las ciencias sociales. Buenos Aires: Emecé, 2007

MATTOS, Carlos. "Falsas expectativas ante la descentralización. Localistas y neoliberales en contradicción". Nueva Sociedad, nro.104, noviembrediciembre, pp. 118-126, 1989.

ORTIZ SANDOVAL, Luis. "La instancia pública de la gestión. Algunas consideraciones sobre la participación ciudadana en el Estado". Revista del CLAD Reforma y Democracia, nro. 54, octubre, 2012.

OSZLAK, Oscar. "Burocracia estatal: política y politicas públicas". POSTData Revista de Reflexión y Análisis Político, vol. 11, abril, pp.11-56, 2006. 
Administración burocrática, de gerencia pública y gobernanza en los programas alimentarios de Argentina desde 1983| María Victoria Sordini

OXMAN, Claudia. La entrevista de investigación en Ciencias Sociales. Buenos Aires: Eudeba, 1998

PETERS, B. (1993) "Política pública y burocracia". Foro Internacional, vol. 33, nro. 1 (131) (Jan. Mar.), pp. 54-87, 1993.

PERELMITER, Luisina. Burocracia plebeya. La trastienda de la asistencia social en el Estado Argentino, Buenos Aires: Unsam edita, 2016.

PLAN VIDA (2000) “Evaluación Plan Vida. Informe Periodo 1994-1999", Área de Evaluación y Sistematización del Plan Vida. La Plata: Consejo Provincial de la Familia y Desarrollo Humano, 2000.

RESTREPO MEDINA, Manuel. "Burocracia, gerencia pública y gobernanza". Revista Diálogos de Saberes, nro. 30, enero-junio, pp. 167-185, 2009.

SCRIBANO, Adrián. E1 proceso de investigación social cualitativo. Buenos Aires: Prometeo, 2008.

SCRIBANO, Adrián. Sociología de los cuerpos/emociones. Revista Latinoamericana de Estudios sobre Cuerpos, Emociones y Sociedad, Vol. 4, $\quad \mathrm{N}^{\circ}$ 10.pp. 93-113, 2012. Disponible en: http://www.relaces.com.ar/index.php/relaces/article/viewArticle/224 Acceso: 12/12/2019.

SCRIBANO, Adrián Y DE SENA, Angélica. Los planes de asistencia social en Buenos Aires: una mirada desde las politicas de los cuerpos y las emociones. Aposta Revista de Ciencias Sociales. $N^{\circ}$ 59, 2013. Octubre Disponible en: http://apostadigital.com/revistav3/hemeroteca/ascribano1.pdf Acceso: $14 / 12 / 2019$.

SOJO, A. La trayectoria del vínculo entre políticas selectivas contra la pobreza y políticas sectoriales. Revista de la CEPAL, (91), 111-131, 2007.

SORDINI, María Victoria. La Entrevista En Profundidad En El ámbito De La Gestión Pública. Revista Reflexiones 98 (1), 75-88, 2018. Disponible en: https://doi.org/10.15517/rr.v98i1.33083 Acceso: 12/12/2019.

SORDINI, María Victoria. El Plan Más Vida en Mar del Plata y el lugar invisible del trabajo femenino: las manos, los ojos y los pies del Estado en el territorio. En: Cena, Rebeca. (comp.) Politicas sociales y cuestión social en la argentina del siglo XXI. Buenos Aires: ESEditora. p. 109 - 130, 2019.

STRAUSS, Anselm y CORBIN Juliet Procedimientos de codificación. Bases de la investigación cualitativa. Técnicas y procedimientos para desarrollar la teoria fundamentada. Antioquia. Contus, 2002. 
Administración burocrática, de gerencia pública y gobernanza en los programas alimentarios de Argentina desde 1983| María Victoria Sordini

TILLY, Charles. The Formation of National States in Western Europe, New Jersey, Princeton University Press, 1975.

VINOCUR, P Y HALPERIN, L Pobreza y politicas sociales en Argentina de los años noventa. CEPAL Santiago de Chile: Naciones Unidas, 2004. 